\title{
Stay on the Cutting-edge of New Technology: Case Study of Gas Turbine Air Filters Durability Enhancement
}

\author{
Mansour Al-Shafei ${ }^{1}$ \& Gasan Alabedi ${ }^{1}$ \\ ${ }^{1}$ Research and Development Center, Saudi Aramco, Dhahran, Kingdom of Saudi Arabia \\ Correspondence: Mansour Al-Shafei, Research \& Development Center, Saudi Aramco, Kingdom of Saudi Arabia. \\ Tel: +966-13-876-4360. E-mail: mansour.shafei@aramco.com
}

Received: June 15, 2017

Accepted: June 27, 2017

Online Published: August 9, 2017

doi:10.5539/jmsr.v6n4p28

URL: https://doi.org/10.5539/jmsr.v6n4p28

\begin{abstract}
The Research and Development Center (R\&DC) of Saudi Aramco has developed new application in ultrasound technology to support the huge networks of crude oil and gas processing facilities, including items of equipment running 24/7.

Gas turbines are playing a vital role in supplying energy to different facilities within the companies and they need complex air filtration systems to operate at high speeds and prevent turbine section components from erosion, fouling, and corrosion. Saudi Aramco's plants have a large number of energy producing gas turbines and the frequent air filter replacement program has become so expensive, that consequently, it has attracted the attention of the plant management to find an appropriate solution for cost reduction.

R\&DC of Saudi Aramco has completed an extensive investigative study to design and examine ultrasonic (sound waves) technology as a practical, easy-to-apply, and cost-effective cleaning procedure to remove the dust and dirt to maximize the lifetime of the air filters. Experimentally, high frequency sound is passed through a cleaning solution, providing waves of high and low pressure. Microscopic bubbles are produced, which implode almost immediately, bringing the cleaning fluid into contact with the surface being cleaned with great force, thereby breaking down dirt particles and cleaning the surface. Using sonic cleaning, it has been found that the filters are not only cleaned from dust and dirt but also from organic materials without affecting the physical integrity of the air filter.

This technical paper benchmarks a technology that has been established to reuse more than 10,000 air filters, which are usually discarded companywide each year. Implementing this technology would not only result in operational cost savings, but also would contribute to the reduction of the local and global environmental impact.
\end{abstract}

Keywords: gas turbine, air filter, ultrasonic, XRD, ESEM, TGA, dust, environment

\section{Introduction}

The gas turbine is an internal combustion engine that ingests a large amount of ambient air during operation (Figure 1) (Al-Shafei \& Alabedi, 2010). The basic principle of the gas turbine engine are: (1) Air is taken from the air suction portion and is supplied into the compressor to be compressed, (2) The compressed air is sent to the combustor, (3) In the combustor, the compressed air and fuel are mixed together to be burned continuously, (4) Expansion and exhaust, where the converted energy is put to use. Due to the combustion process, high temperature and high-pressure combustion gas are generated to be supplied into the turbine portion. By expansion of the combustion gas, moving blades of the turbine portion are driven to rotate a rotor and thereby to generate an electric power.

A filtration system (Figure 2) is used to control the quality of the air entering the turbine to enhance its performance and lifetime. The selection of the filtration system can be a daunting task, because there are many factors to consider. The system should be selected based on the operational conditions and goals for the turbine, the contaminants present in the ambient air, and expected changes in the contaminants in the future due to several changes, such as seasonal changes (2). 


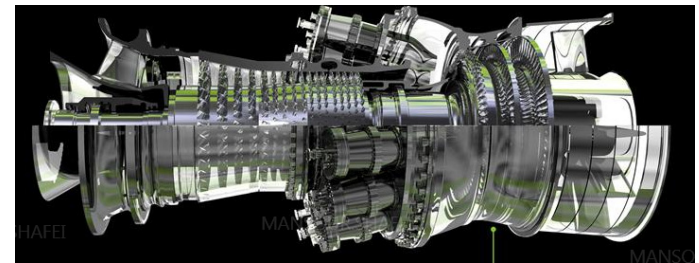

Figure 1. Gas turbine cross-sectional

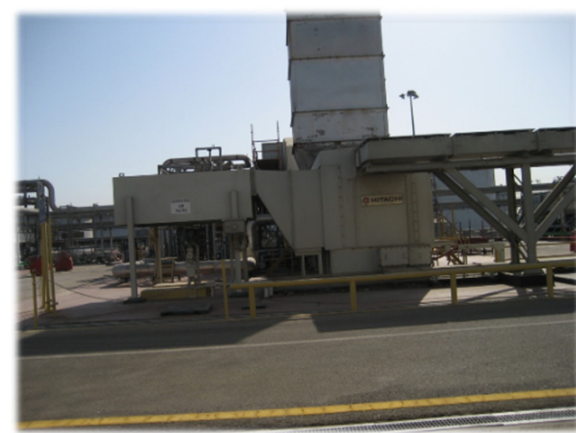

Figure 2. Gas turbine filtration system

\subsection{Filtration Mechanisms}

There are different filtration systems that use various mechanisms to remove contaminants from the air. Such systems will influence the removal of contaminants, which depend on the filter media, fiber size, packing density of the media, particle size, and electrostatic charge (Blackstone Ney Ultrasonic, 2009).

Currently, there are five filtration mechanisms available in the industry:

a. Inertial impaction. This type of filtration is applicable to particles larger than $1 \mu \mathrm{m}$ in diameter.

b. Diffusion. This is effective for very small particles typically less than $0.5 \mu \mathrm{m}$ in size.

c. Interception. Interception occurs with medium-sized particles that are not large enough to leave the flow path due to inertia or not small enough to diffuse.

d. Sieving is the situation where the space between the filter fibers is smaller than the particle itself, which causes the particle to be captured and contained.

e. Electrostatic charge. This type of filtration is effective for particles in the range of 0.01 to $1 \mu \mathrm{m}$ size (Blackstone Ney Ultrasonic, 2009).

\subsection{Components of a Filtration System}

There are no universal filter that will eliminate all contaminants. Therefore, two-stage or three-stage filtration systems are recommended to be used to protect gas turbine components from damage. In the industry (Figure 3), a prefilter or weather louver can be used first to remove contaminants such as solid erosive particles, rain, etc. The second stage is a low to medium performance filter that can be used to remove finer sized solid particles. The third filter is usually a high performance filter to remove smaller particles less than 2 microns in size from the air. High efficiency cartridge filters with a pulse cleaning system are used in severe conditions (sandstorm weather). Such system keeps the pressure loss below acceptable levels by constant cleaning without any interaction of the gas turbine operator. This allows the gas turbine to continue to operate at an optimal performance even during adverse conditions. Subsequently, the use of the pulse cleaning system should be cautioned. If the environment has high humidity, fog, or moisture or contaminants with sticky particles (such as pollen), the particles will cake on or stick to the cartridge filter elements and cannot be removed with the air pulses. Some levels of moisture and sticky particles can be tolerated, but the filters must then be replaced to regain the original condition with new clean filters. If moisture is present due to fog or high humidity, then an additional stage with a coalescer and vane axial separator should be considered (Gas Machinery Research Council Southwest Research Institute, 2010).

To protect the gas turbine from the variety of contaminants present in the ambient air, several filtration devices are used to achieve certain purposes.

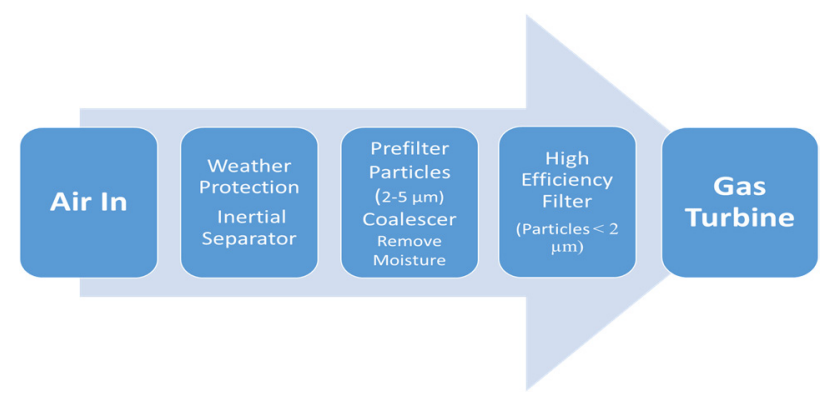

Figure 3. Multistage filtration system 


\subsubsection{Weather Protection and Trash Screens}

Weather louvers or hoods and trash screens are the most simplistic of the filtration mechanisms, but they are important to reduce the amount of moisture and solid contaminants, which enter the main filtration system. These are not classified as filters, but they are part of the filtration system and provide assistance in removal of large objects or contaminants carried in the flow stream (Gas Machinery Research Council Southwest Research Institute, 2010).

\subsubsection{Inertial Separators}

Inertial separation takes advantage of the physical principles of momentum, gravity, centrifugal forces, and impingement, and the physical difference between phases to cause particles to be moved out of the gas stream in such a way that they can be carried off or drained. The higher momentum of the dust or water particles contained in the air stream causes them to travel forward, while the air can be diverted to side ports and exit by a different path than the dust (Gas Machinery Research Council Southwest Research Institute, 2010).

\subsubsection{Prefilters}

The air has a mixture of large and small particles. If a one-stage high efficiency filter is used, the buildup of large and small solid particles can quickly lead to increased pressure loss and filter loading. Prefilters are used to increase the life of the downstream high efficiency filter by capturing the larger solid particles greater than $10 \mu \mathrm{m}$. Therefore, the high efficiency filter only has to remove the smaller particles from the air stream, which increases the filter life. In many installations, the prefilters can be exchanged without having to shut the engine down (Gas Machinery Research Council Southwest Research Institute, 2010).

\subsubsection{Moisture Coalescers}

In environments with a high concentration of liquid moisture in the air, coalescers are required to remove the liquid moisture. The coalescer works by catching the small water droplets in its fibers. As the particles are captured, they combine with other particles to make larger water droplets. Coalescers are designed to allow the droplets to either drain down the filter or be released back into the flow stream. If the larger drops are released, then they are captured downstream by a separator.

\subsubsection{High-Efficiency Filters}

There are filters for removing larger solid particles, which prevent components erosion. Smaller particles, which lead to corrosion and fouling, are removed with high efficiency filters. These types of filters have average separations greater than $80 \%$.

\subsubsection{Self-Cleaning Filters}

Filter Materials. There are different types of self-cleaning filters. The components of each filter determine its efficiency, cleanability, long life and stability.

Each set of self-cleaning filters consist of a cylindrical and a conical element. Top and bottom caps are made of pressed or spun galvanized steel (Figure 4). A rigid expanded metal inner core supports the media pack and prevents the element from collapsing under conditions of extreme differential pressure.

The filter media is water repellent and is corrugated perpendicularly to the pleat direction to ensure even spacing of pleats and prevent their collapse. The filters are composed of a resin impregnated mixture of cellulose and synthetic fibers.

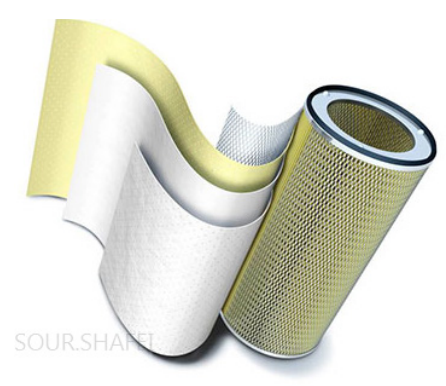

Figure 4. Layers of filter materials
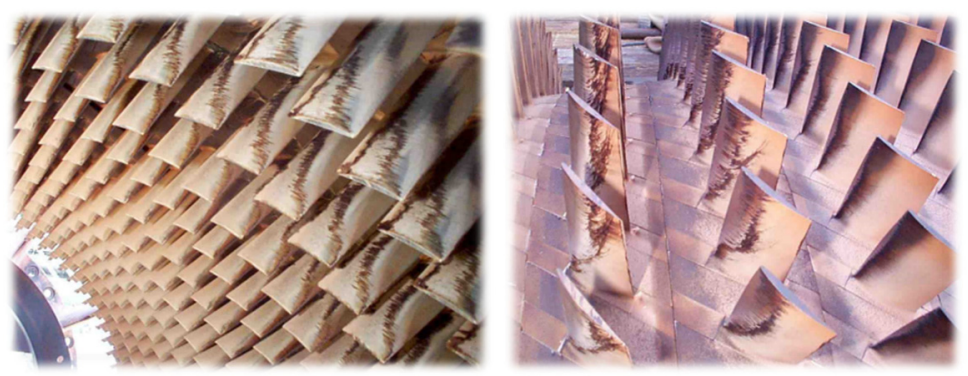

Figure 5. Fouling in both rotor and stator caused by poor filtration 


\subsection{Failures of Gas Turbine}

When the quality of the air entering the gas turbine is not well controlled, there are several consequences that can occur (Figure 5), such as erosion, fouling, and corrosion that cause critical failures of the gas turbine.

\subsubsection{Erosion}

Erosion occurs when solid or liquid particles approximately $10 \mu \mathrm{m}$ and larger impact rotating or stationary surfaces in the gas turbine. The particles will impact the surface and remove tiny particles of metal, which eventually lead to changes in the geometry of the surface (Al-Shafei \& Alabedi, 2010; Blackstone Ney Ultrasonic, 2009; Gas Machinery Research Council Southwest Research Institute, 2010).

\subsubsection{Fouling}

Fouling of compressor blades is an important mechanism leading to performance deterioration in gas turbines over time. Particles that cause fouling are typically smaller than 2 to $10 \mu \mathrm{m}$ (Al-Shafei \& Alabedi, 2010; Blackstone Ney Ultrasonic, 2009; Gas Machinery Research Council Southwest Research Institute, 2010; FC, 2008; Carl, 2011).

\subsubsection{Corrosion}

When chemically reactive particles adhere to surfaces in the gas turbine, corrosion can occur.

\subsection{Saudi Aramco Plant}

The Saudi Aramco DeskTop Standard "32-SAMSS-O08" is used to ensure the ability of an inlet air filtration system for combustion gas turbines to withstand the rigid environmental conditions in a high ambient dust desert area with relative humidity ranging from zero to $100 \%$. During normal operation, ambient air flows downwards into the filtration system through inlet hoods (Figure 6), which protect the filters from the effects of a harsh environment. These inlet hood deflectors direct the incoming air downwards. The incoming air is cleaned by filters and then passes through to the turbine.

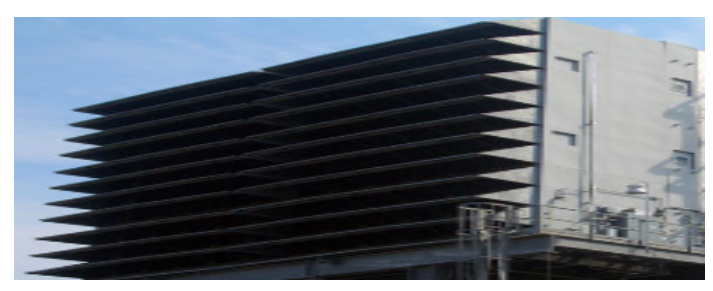

Figure 6. Inlet hood deflectors (Klima-Service, n.d.)

Clogging occurs due to the accumulation of dust particles in each of the filters after long-term use and the filter must be replaced to prevent the deferential pressure $(\Delta \mathrm{P})$ drop across the filtration system and possible damage to the first and second stage turbine blades and other components due to the rupture of the filter itself, Figure 7. According to the manufacturer recommendations, the expected lifetime of the filters in operation is two years and five years, starting from the production date, however, filters at most of the plants last for only six months. To minimize the running costs and environmental impact caused by discharging large amounts of used gas turbine air filters, plant engineers started a pilot experimental cleaning procedure utilizing a hydrojetting air filter cleaning approach.

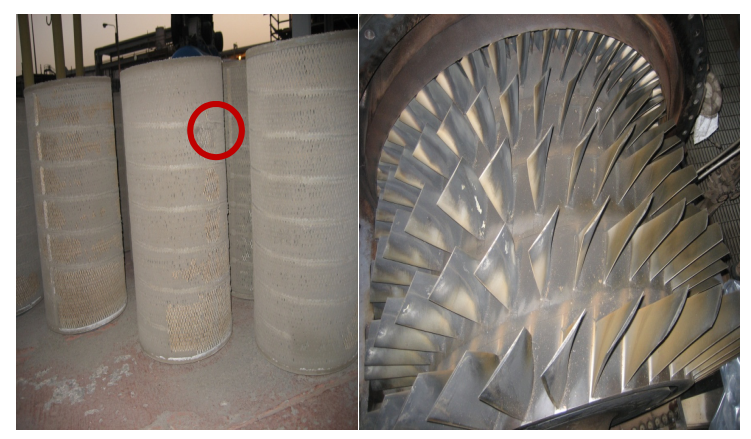

Figure 7. Effect of clogged and damaged air filter (circled) on the turbine blades 


\subsection{Industrial Cleaning Systems}

Cleaning has been part of the manufacturing industry for centuries to protect equipment from failure; however, processes have been modified due to the latest development in technology. Cleaning by dipping, soaking or spraying with liquid cleaners is a common process in the manufacturing industry. "Industrial Washers and Cleaning Systems" Milacron Marketing LLC Technical Report No. 6/07 Page 1 of 2 Original 6/07.

There are different systems used in industry to perform cleaning:

\subsubsection{Immersion Cleaning}

This system is an effective and simple method of parts washing. It involves immersing a part directly into a liquid cleaning agent. This system is not applicable for cleaning air filters, which are used to prevent damage to the gas turbine because water and detergents could cause damage to the filter components (Milacron Marketing LLC, n.d.).

\subsubsection{Auger Washers}

These are generally combination systems where parts are drawn through immersion baths and subsequently sprayed with the same solution. This system is not valid for cleaning air filters because it could probably ruin the micro-filter components (Milacron Marketing LLC, n.d.).

\subsubsection{Vibratory Cleaning}

Typically these systems are used for de-burring, pre-plating, and de-scaling processes. The machinery delivers mechanical energy to the media, cleaning compounds, and parts to achieve the desired finish. This system is not valid for cleaning air filters because it is used for cleaning steel components.

\subsubsection{Spray Washers}

In this process, parts are cleaned with a directed, pressurized spray of hot water, detergent or cleaning solution, which is generally alkaline (Milacron Marketing LLC, n.d.).

This system is not valid for cleaning air filters because it could probably damage the air filter components.

\subsubsection{Hydrojetting}

The hydrojetting cleaning technique (Figure 8 ) has been used to remove dust from gas turbine air filtration systems. Information received from plant engineers suggested that the method has been tested and given excellent results with deferential pressure $(\Delta \mathrm{P})$ across the filtration system after the cleaning process decreased to a desired reading. This system is not valid for cleaning air filters because the pressure will probably ruin the air filter components.

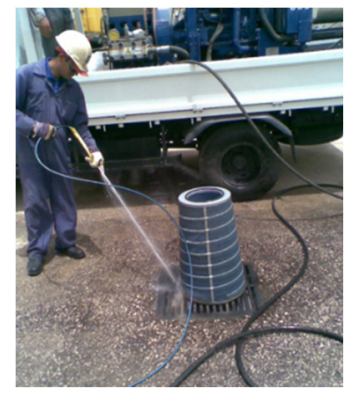

Figure 8. Hydrojetting cleaning

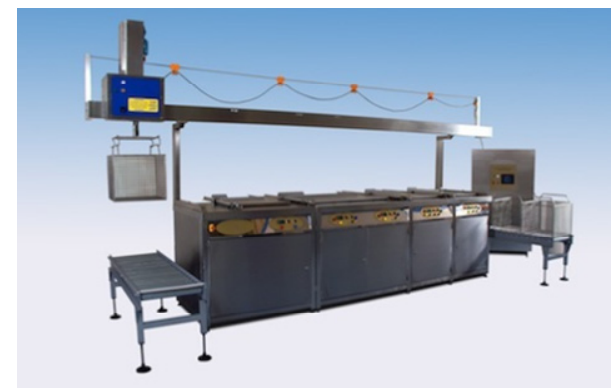

Figure 9. Ultrasonic cleaning systems (Filtration components, n.d.)

\subsubsection{Ultrasonic}

Ultrasonic (frequencies above 18 Kilohertz) (Figure 9) is the science of sound waves above the limits of human audibility. High frequencies produce high or treble tones. The frequencies used in this work was in the range from $20 \mathrm{KHz}$ to over $50 \mathrm{KHz}$.

An alternative gas turbine air filter cleaning procedure method utilizing ultrasonic cleaning was identified as a potential alternative approach. This is because it is considered safe for most sensitive and microscopic fibers. Ultrasonic cleaning technology has become the preferred method of cleaning in the industry today. The development of the many different types of ultrasonic cleaners able to use water-based chemicals, solvents or used in conjunction with vapor degreasing has put ultrasonic as the first choice in targeting cleaning. 
Ultrasonic cleaning systems are so diverse (Figure 8); they are used in almost every cleaning application from metals through to plastics, in industries such as automotive, electronics, printing and engineering. Ultrasonic cleaners are fast, efficient, consistent, not labor intensive and low maintenance.

Since the effects of thousands of implosions per second are very powerful, the cleaning process is safe because the energy is localized at the microscopic level. The most important caution is the choice of cleaning solution. Potentially adverse effects of the detergent on the material being cleaned will be enhanced by the ultrasonic waves (Milacron Marketing LLC, n.d.).

Ultrasonic cleaners are used at frequencies from $20 \mathrm{kHz}$ to $40 \mathrm{kHz}$ for different industrial applications. The ultrasonic cleaner works mostly by energy released from the collapse of millions of microscopic cavitations near the dirty surface. The bubbles made by cavitation collapse forming tiny jets directed at the surface. Cavitation is the rapid formation and collapse of millions of tiny bubbles (or cavities) in a liquid. Cavitation is produced by the alternating high- and low-pressure waves generated by high frequency (ultrasonic) sound. During the low-pressure phase, these bubbles grow from microscopic size, until, during the high-pressure phase, they are compressed and implode.

There are many important variables that should be understood before using the ultrasonic cleaning methodology. Optimizing these variables will produce the best cleaning. The most important decisions to be made are choosing the proper cleaning solution, cleaning at the right temperature for the correct amount of time, and choosing the right size and type of ultrasonic cleaner.

The selections of purified water and cleaning detergents (solid or liquid forms) are essential factors for this application. The effectiveness of a cleaning solution is to break the bonds between the filter cartridge's fine fibers and their soil. Water alone has no cleaning properties. The primary purpose of the ultrasonic activity (cavitation) is to assist the solution in doing its job. An ultrasonic cleaning solution contains various ingredients designed to optimize the ultrasonic cleaning process. For example, increased cavitation levels result from reduced fluid surface tension. An ultrasonic solution will contain a good wetting agent or surfactant.

Modern ultrasonic cleaning solutions are compounded from a variety of detergents, wetting agents and other reactive components. A large variety of other formulations are commercially available, designed for specific applications. Proper selection is crucial for acceptable cleaning activity and to preclude undesirable reactivity with the part being cleaned. Cleaning time will vary, depending on particle properties, solution, temperature and the degree of cleanliness desired. Highly visible removal of soil should start almost immediately after the ultrasonic cleaning action begins.

Cleaning time adjustment is the easiest factor used to compensate for process variables. The effectiveness of cleaning usually depends on improper control of one or more process variable(s); such as choosing the wrong detergent solution, insufficient heat, or not allowing enough time for the particular soil to be removed.

Another important factor that enhances and speeds up the cleaning process, and most detergent solutions are designed to work best is at an elevated temperature. The best way to determine the optimum temperature, which will give the fastest, cleanest and safest results, is to run tests. Usually, for this application the best results are within the $50{ }^{\circ} \mathrm{C}$ to $65^{\circ} \mathrm{C}$ range. Additionally, cleaning with distilled or deionized water will be effective for removing any chemical residue, which could be harmful to the air filter's fine polymeric fibers (Ultra-sonic cleaning system, n.d.).

\section{Experimental Section}

To have an effective cleaning methodology to the existing air filtration system used to protect plant gas turbine from damage. The following procedures were carried out to evaluate filtration cartridge before and after cleaning:

1) Determination of mineralogical composition of residual particles present in the filters.

2) Extensive examination of new, used, and cleaned air filter layers to provide information on the physical and chemical nature of fibers.

3) Identification of the content of organic and inorganic materials of the filter samples before and after the cleaning procedure.

4) Determination of the degradation of polymer fibers that might be incurred due to handling.

5) Determination of $\mathrm{pH}$ level of water used for the cleaning procedure. Water used for cleaning with high or low $\mathrm{pH}$ level may cause damage to the air filter's components.

6) Identification and examination of alternative air filter's cleaning method. 


\subsection{Air Filter Sample Preparations}

Supplied air filter samples were cross-sectional cut (Figure 10a) to obtain representative samples for visual examination of cartridges and metallic cages. Air filter samples were dried cut to preserve their original integrity. Dust particles were carefully collected of used air filters to be analyzed by environmental scanning electron microscope (ESEM), X-ray powder diffraction (XRD), and particle size analyzer to determine their mineral compositions and particle size measurements.

A special air filter sample holder (Figure 10b) was designed and constructed at the R\&DC of Saudi Aramco to hold samples during ultrasonic treatment. Carefully chosen air filter representative samples were fitted into the sample holder, Figure 10c.

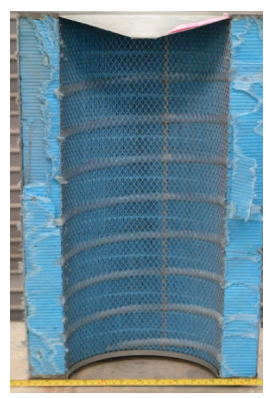

(a)

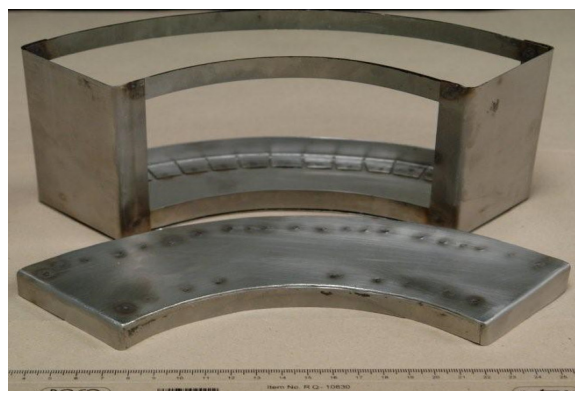

(b)

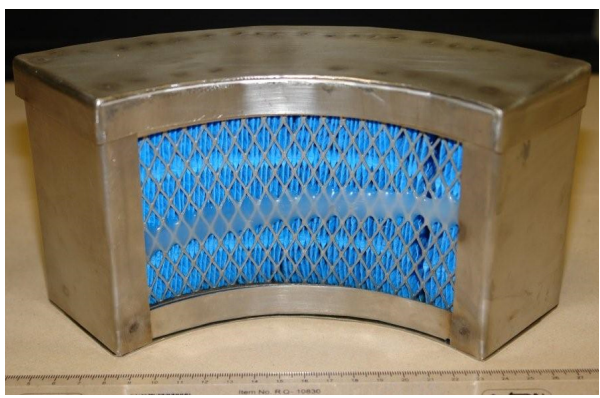

(c)

Figure 10. (a) Cross-sectional of used air filter, (b) special air filter sample holder, and (c) air filter cartridge inside the holder

\subsection{Water Chemical Analysis}

Chemical analyses of plant water used for cleaning filters were analyzed to determine $\mathrm{pH}$ values, conductivity and mineral content utilizing several ISO R\&DC approved testing procedures.

\subsection{ESEM/Energy Dispersive Spectroscopy (EDS) Analysis}

New (used as a reference), spent, hydrojetting, ultrasonically cleaned air filter cartridges were analyzed for morphological and elemental compositional analyses. The analyses were performed according to the accredited Saudi Aramco Laboratory Method (SALAM) testing procedure. The Quanta 400 and XL30 ESEMs operated at $15 \mathrm{kV}$ acceleration potential, 0.23 Torr water vapor pressure and $11.00 \mathrm{~mm}$ working distance were used to conduct the analyses. Also, backscattered electron images and EDS spectra were acquired from all the samples components.

\subsection{X-Ray Powder Diffraction (XRD)}

The XRD method was used to identify the crystalline phases/compounds of dust samples. Determination of mineralogical composition of residual particles before the cleaning procedure was carried out by XRD analytical technique. The residual particle XRD is one of the primary techniques that used to examine the physic-chemical composition of unknown residual particles.

\subsection{Particle Size Distribution Analysis}

The_particle size distribution measurements were conducted utilizing Mastersizer 2000/5.1 to determine the average size of residual particles attached to filters cartridges components. This instrument is capable of measuring particle sizes in the range of $10 \mathrm{~nm}$ to $2 \mathrm{~mm}$.

\subsection{Ultrasonic Cleaning Procedures}

The immersible ultrasonic cleaning system is working on principles of Piezo electric transducers, which are attached to the cleaning tank and they generate ultrasound waves that vibrate the cleaning fluid at very high velocity, creating a process called cavitation. Millions of tiny bubbles implode within the solution and penetrate into every orifice of the item being cleaned, removing dirt and grime efficiently.

\subsection{R\&DC Ultrasonic Housing Design}

In the R\&DC we have developed an innovative chair to hold the spent air filter during the ultrasonic wave washing process. The housing unit has been built to achieve the desired objectives of high cleaning efficiency in a timely manner. 
Figure 11 is a diagram of the ultrasonic wave washing unit housing, with a special chair, to hold the spent air filter during the washing process.
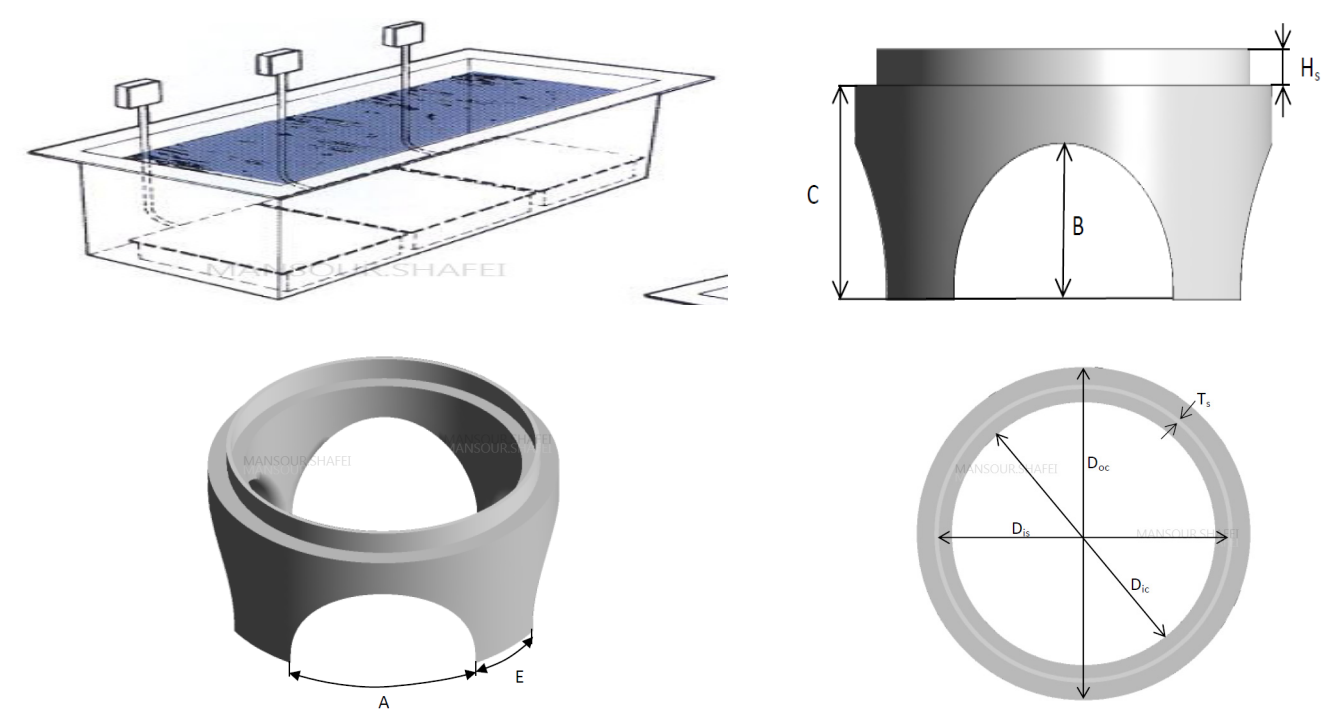

Figure 11. Immersible tank configuration: A special chair to hold air filter inside the ultrasonic bath

Different conditions and cleaning procedures were used to identify and determine the cleaning efficiency and their effect on the structures of cleaned air filters. Table 1 shows the conditions and cleaning procedures carried out for this study.

Table 1. Ultrasonic cleaning programs conditions

\begin{tabular}{|c|c|c|c|c|c|c|c|c|c|}
\hline & \multicolumn{2}{|c|}{ Frequency $50 / 60 \mathrm{~Hz}$ at } & \multicolumn{2}{|c|}{$\begin{array}{c}\text { Dissolved Powder Detergent } \\
\text { for Min }\end{array}$} & \multirow[t]{2}{*}{$\begin{array}{l}\text { De-ionized Water } \\
\quad \text { for } 15 \mathrm{Min}\end{array}$} & \multicolumn{2}{|c|}{$\begin{array}{l}\text { Liquid Detergent } \\
\text { for } 15 \text { Min at }\end{array}$} & \multicolumn{2}{|c|}{$\begin{array}{c}\text { Water with Low Salt } \\
\text { for Min }\end{array}$} \\
\hline & $25^{\circ} \mathrm{C}$ & $50^{\circ} \mathrm{C}$ & 15 & 30 & & $25^{\circ} \mathrm{C}$ & $50^{\circ} \mathrm{C}$ & 15 & 30 \\
\hline Program 1 & $\sqrt{ }$ & & & & & & $\sqrt{ }$ & $\sqrt{ }$ & \\
\hline Program 2 & $\sqrt{ }$ & & & & & & & & $\sqrt{ }$ \\
\hline Program 3 & $\sqrt{ }$ & & $\sqrt{ }$ & & & & & & \\
\hline Program 4 & $\sqrt{ }$ & & $\sqrt{ }$ & & $\sqrt{ }$ & & & & \\
\hline Program 5 & $\sqrt{ }$ & & & $\sqrt{ }$ & $\sqrt{ }$ & & & & \\
\hline Program 6 & $\sqrt{ }$ & & & & & $\sqrt{ }$ & & $\sqrt{ }$ & \\
\hline Program 7 & & $\sqrt{ }$ & & & & $\sqrt{ }$ & & $\sqrt{ }$ & \\
\hline Program 8 & & $\sqrt{ }$ & & & & & $\sqrt{ }$ & $\sqrt{ }$ & \\
\hline
\end{tabular}

\section{Results and Discussions}

The ESEM cross-sectional images of new cartridge air filter components (Figure 12) showed that the air filter is constructed of multiple layers of polymeric fibers, approximately $500 \mu \mathrm{m}$ thick. The micro-meter porous openings were covered with a polymeric material web-like structure, and further morphology observations of the samples revealed that the cartridges had a lot of spaces between the layers, which presumably were designed to capture and prevent small dust particles from penetrating the filter. 


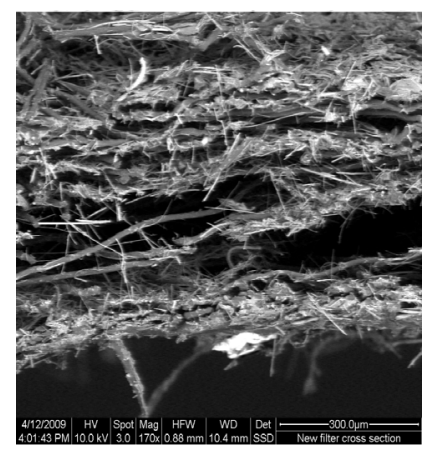

(a)

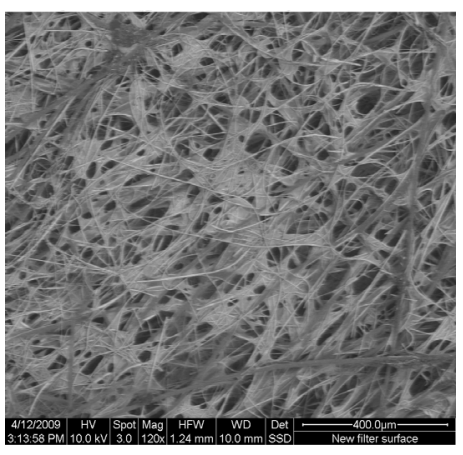

(b)

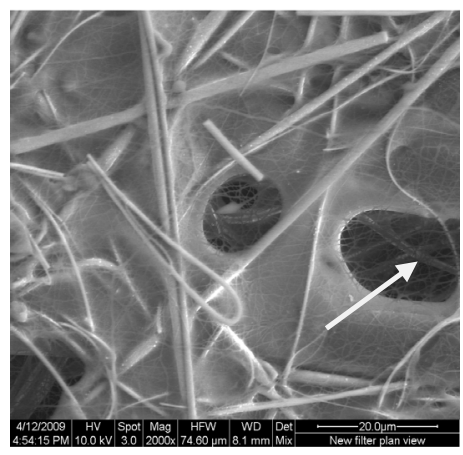

(c)

Figure 12. (a) Cross-sectional image of new air filter polymeric fiber cartridge, (b) and (c) surface image of new air filter polymeric fiber cartridge

The ESEM image of the used air filter cartridge sample (Figure 13) showed that the cartridge openings were completely blocked with dust. The major distribution of particles captured by the air filter were found to be between $1 \mu \mathrm{m}$ up to $60 \mu \mathrm{m}$ in size. The EDS micro-chemical analysis (Figure 13) indicated that the main elements were $\mathrm{Si}, \mathrm{Al}, \mathrm{Ca}, \mathrm{Mg}$ and $\mathrm{O}$ with traces of $\mathrm{Fe}, \mathrm{Na}, \mathrm{S}, \mathrm{Cl}$, and $\mathrm{K}$.
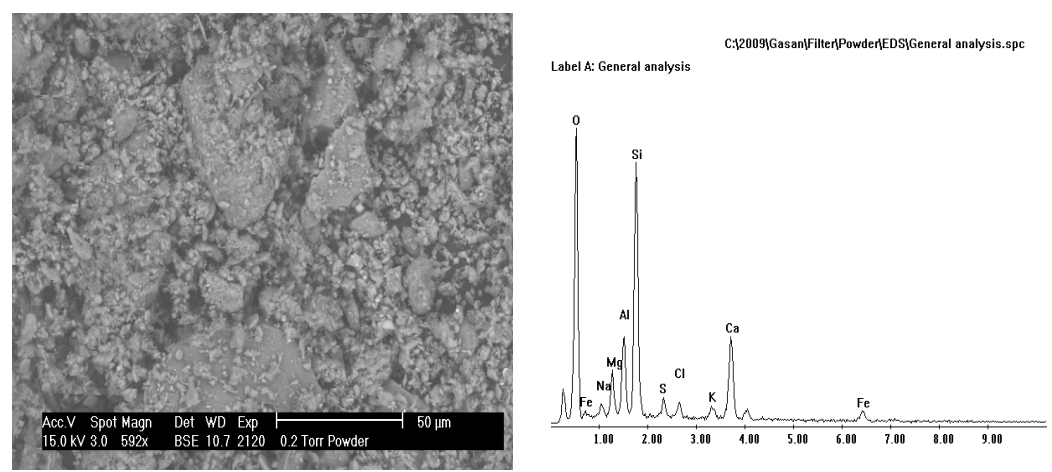

Figure 13. Backscattering ESEM image and EDS spectrum of dust particles collected from used air filters

Residual samples (adhered to the cartridge) were analyzed for particle size measurements. The resulted data showed that the mean dust particle size was around $10 \mu \mathrm{m}$ as shown in Figure 14, which was in good agreement with analyses conducted by the ESEM technique.

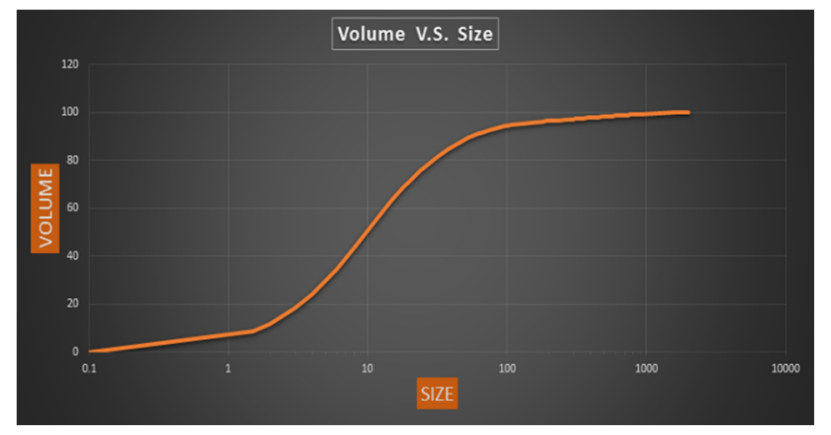

Figure 14. Particle size analysis of residual powder

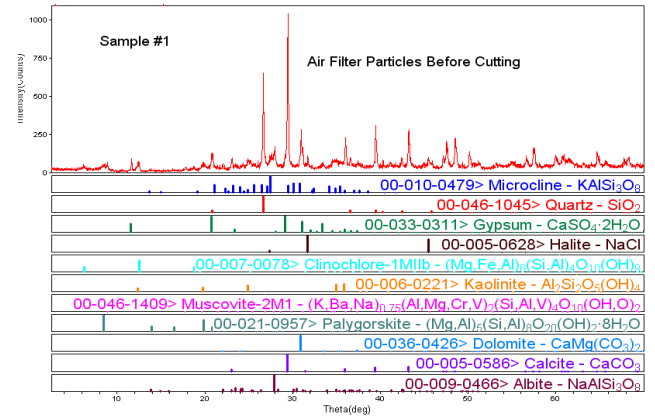

Figure 15. XRD spectrum of filter dust 
The chemical composition carried out by XRD (Table 2 and Figure 15) showed that the dust sample was composed of calcite $\left(\mathrm{CaCO}_{3}\right)$, quartz $\left(\mathrm{SiO}_{2}\right)$ and dolomite $\left(\mathrm{Ca}, \mathrm{Mg}\left(\mathrm{CO}_{3}\right)_{2}\right)$ with minor amounts of Palygorskite- $(\mathrm{Mg}, \mathrm{Al})_{2}$ $\mathrm{Si}_{4} \mathrm{O}_{10}(\mathrm{OH}) \cdot 4\left(\mathrm{H}_{2} \mathrm{O}\right)$, Muscovite-(K,Ba, $\left.\mathrm{Na}\right)_{0.75}(\mathrm{Al}, \mathrm{Mg}, \mathrm{Cr}, \mathrm{V})_{2}(\mathrm{Si}, \mathrm{Al}, \mathrm{V})_{4}(\mathrm{OH}, \mathrm{O})_{2}$, Gypsum-CaSO ${ }_{4} \cdot 2 \mathrm{H}_{2} \mathrm{O}$ chlorite-

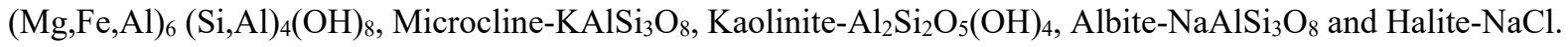

Table 2. Minerals composition of filters dust obtained by XRD analysis

\begin{tabular}{lclc}
\hline Phase Identified & Particles Wt.\% & Phase Identified & Particles Wt.\% \\
\hline Calcite- & 44 & Microcline & 3 \\
Quartz & 14 & Kaolinite & 3 \\
Dolomite & 10 & CaSO4. 2H2O & 2 \\
Palygorskite & 8 & Albite-NaAlSi3O8 & 2 \\
Muscovite & 9 & Halite-NaCl & 1 \\
Chlorite & 4 & & \\
\hline
\end{tabular}

To apply for a cost-effective cleaning procedure to maximize the lifetime of the air filters; a spent air filter was cleaned in the plant applying the hydrojetting cleaning methodology and the cleaned filter was delivered along with the water samples used for cleaning to the R\&DC for a comprehensive chemical and physical assessment. The analyses data showed: (1) $\mathrm{pH}$ level of used water was 7.8, and (2) presence of alkaline compounds: magnesium, sodium and calcium were observed. The presence of high salts as well as chlorides could have an effect on polymeric-based fibers of the air filters, which end up affecting air filtration output. Also, ESEM/EDS imaging and micro-chemical analysis was conducted. The collected images obtained showed that there were traces of dust and sodium chloride particles adhered on the fibers, which significantly affected the polymer fiber's properties. Additionally, major changes in the microstructures of cartridges were observed as shown in Figure 16, such as the web-like structures were completely dispersed or damaged, which most probably was due to hydrojet water pressure applied on the spent air filter cartridge during the cleaning process. Such a method cannot be applied since it has caused severe damage to the filter's components.

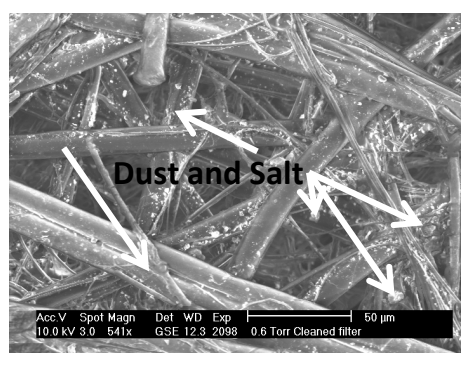

(a)

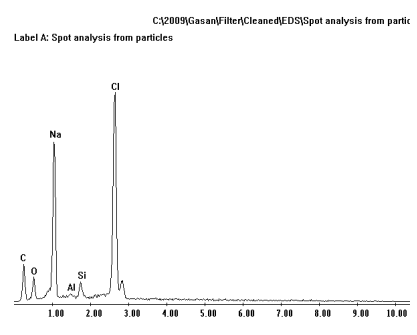

(b)

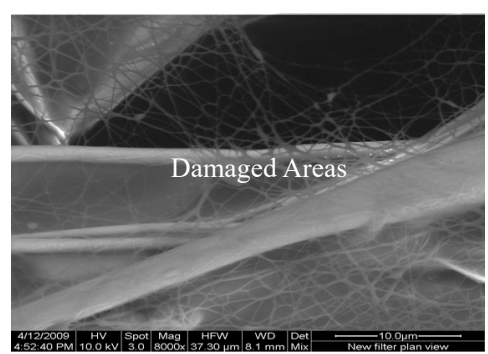

(c)

Figure 16. Backscattering ESEM images of hydrojetting cleaned air filters (a) damaged air filter net-like structure (b) dust and salt particles adhered on the fibers, and (c) EDS spot analysis of residual particles attached to air filter

The ultrasonic cleaning program was applied according to the conditions highlighted in Table 1. High resolution ESEM images presented air filter samples cleaned by the ultrasonic cleaning method applying Programs 1 and 2. As indicated in Figure 17, the ultrasonic method has better cleaning efficiency that could be contributed to the cavitation effect of the ultrasonic wave targeting the dust particles.

Duration of the ultrasonic cleaning procedure was extended for an additional 15 minutes. High resolution ESEM images, Figure 17b, showed that there was no improvement in terms of dust removal from the filter microcomponents compared to the previous method (15 minutes), however, traces of dust particles were still detected inside the cavities of the air filter's fibers. 


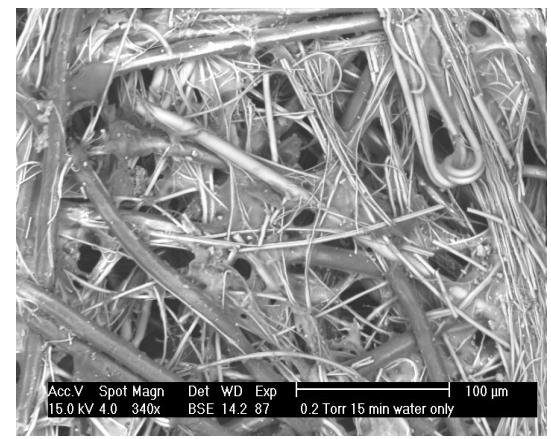

(a)

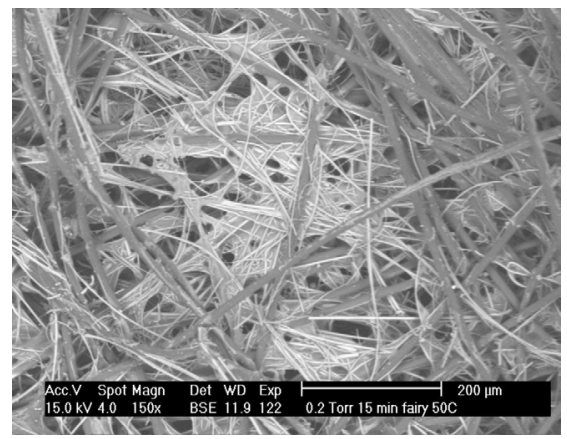

(b)

Figure 17. ESEM images of the ultrasonic method for 15 minutes

Ultrasonic cleaning procedures using dissolved powder detergent (Programs 3, 4 and 5) for the air filters was also examined. As shown in the ESEM images in Figure 18, the utilization of powder detergent deteriorated the filter components due to strong adherences of undissolved detergent solid particles to the filter's fibers compared to previous filter samples cleaned with water.

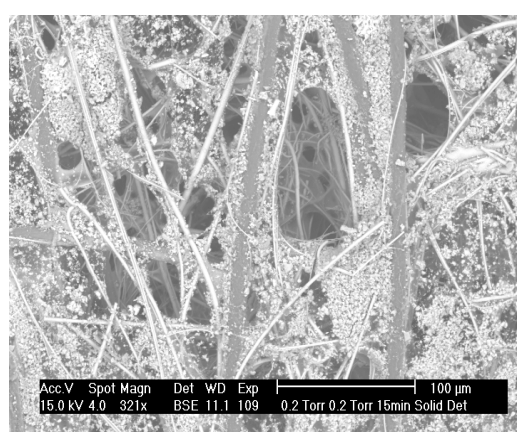

(a)

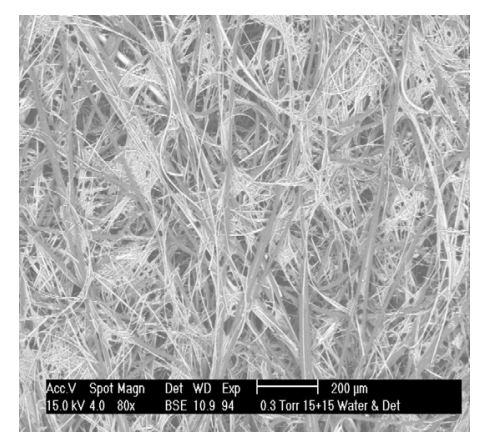

(b)

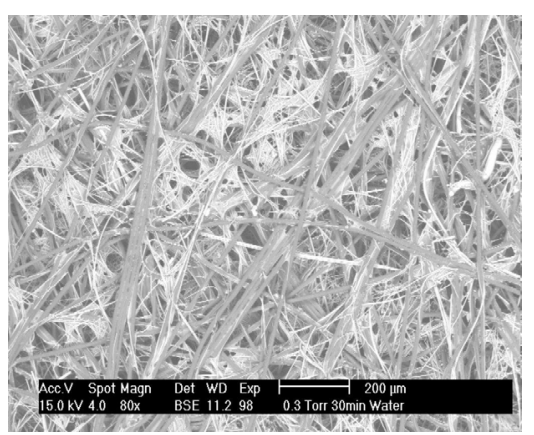

(c)

Figure 18. ESEM images of air filter cartridge ultrasonically cleaned for 15 minutes at room temperature using

(a) dissolved powder detergent (b) dissolved powder detergent and de-ionized water for 15 minutes, and (c) dissolved powder detergent with de-ionized water for 30 minutes

Varying the experimental conditions according to Program 4 (using de-ionized water for an additional 15 minutes) resulted in better cleaning efficiency, Figure 18c. The output result was probably due to elongation of the cleaning duration as the dependency of ultrasonic cleaning efficiency on time as previously mentioned.

Further studies were conducted to examine the effect of other cleaning agents in the spent air filters based on the ESEM micro-image observations. Commercially available liquid detergent was used as a cleaning agent. Numerous cleaning experiments were conducted to optimize $\mathrm{pH}$ values and soaking time. According to Program 6, the air filter was cleaned at room temperature for 15 minutes (Figure 19). The ESEM images showed improvement in dust removal from air filter components compared to those cleaned with solid detergent at the same experimental conditions.

More improvements to air filter cleaning were observed after using liquid detergents followed by water cleaning for 15 minutes each. Closed ESEM morphology examinations showed there were still some dust particles present in the air filter cartridge.

The effect of elevated temperature $\left(50^{\circ} \mathrm{C}\right)$ on cleaning conditions was also explored (Figure 19) in combination with liquid detergent. Closed ESEM morphology examinations showed most of the dust particles were completely removed from the air filter components. Moreover, the ESEM images (Figure 19d) showed that the air filter components, especially the fine fibers, were not affected due to cleaning methodology. 


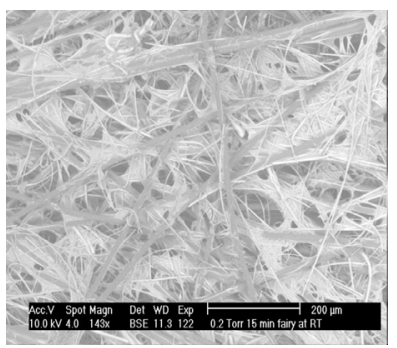

(a)

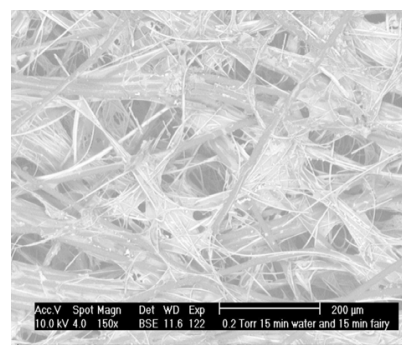

(b)

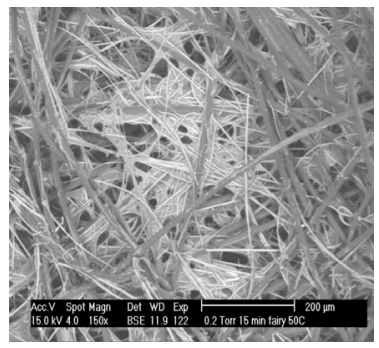

(c)

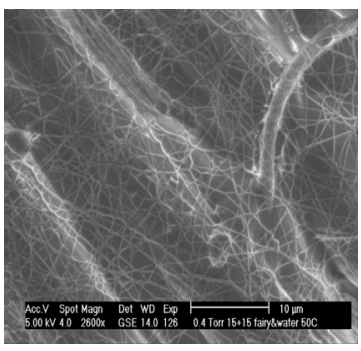

(d)

Figure 19. ESEM images of an air filter cartridge ultrasonically cleaned with liquid detergent at room temperature for (a) 15 minutes, (b) followed by water for 15 minutes each, (c) followed by water for 15 minutes at $50{ }^{\circ} \mathrm{C}$, and (d) followed by water cleaning for 15 minutes each at $50{ }^{\circ} \mathrm{C}$

\section{Conclusions}

This paper presents experimental design and implementation of ultrasonic (sound wave) cleaning technology as a practical, easy-to-apply, and cost-effective cleaning procedure to remove dust and dirt to maximize the lifetime of the air filters. Nevertheless, the hydrojetting cleaning methodology was also evaluated. It has drawbacks to be used in cleaning air filters. Based on our examinations and observations we conclude the following:

- There was a presence of high amounts of salt elements in the raw water samples used for air filter hydrojetting cleaning and the presence of salts on the cleaned filter fibers could have an effect on the properties of polymer fibers of the cartridge.

- The observation of distortions on the hydrojetting cleaned filter cartridge sample could have occurred during the jet cleaning process due to extensive water jet pressure force applied on the filter cartridges. This distortion can affect the efficiency of cleaned air filtration of fine dust particles.

- Ultrasonically cleaned samples showed better cleaning efficiency compared to samples cleaned by hydrojetting pressure system.

- The ultrasonic cleaning efficiency depends on the cleaning duration, temperature and cleaning detergent.

- Closer ESEM image analyses showed that the ultimate conditions of ultrasonic cleaning method can be achieved for samples cleaned with liquid detergents at $50 / 60 \mathrm{~Hz}, 50{ }^{\circ} \mathrm{C}$ followed by water cleaning for 15 minutes each.

- This technology has been designed as practical, easy-to-apply, and cost-effective cleaning procedure to reclaim resources and minimize environmental impact. This is based on extending the replacements of the gas turbine air filters.

\section{References}

Al-Shafei, M. A., \& Alabedi, G. (2010). Investigation of the Effect of HydroJetting Cleaning Procedure and its Impact on the Performance of Gas Turbine Air Filters at Abqaiq Plants. final report, July 2010.

Blackstone Ney Ultrasonic. (2009). Fundamentals of Ultrasonic and Megasonic Cleaning. Reprinted from the November/December 2009 PROCESS CLEANING Magazine and Copyright (C) 2009 by Gardner Publications, Inc., 6915 Valley Ave., Cincinnati, Ohio 45244-3029.

Carl. (2011). Air Purifier Technologies: HEPA Filter. Retrieved from http://air-purifier-reviewsite.com/featured/ air-purifier-technologies-hepa-filter/

FC. (2008). Does smaller particle always penetrate filters easier? In Totobobo mask, High Tech Pollution Mask for children and adults. Retrieved from http://totobobo.com/blog/2008/08/does-smaller-particle-always penetrate-filters-easier/

Filtration components. (n.d.). Retrieved from http://www.gore.com/en_xx/products/filtration/

Gas Machinery Research Council Southwest Research Institute. (2010). Guideline for Gas Turbine Inlet Air Filtration Systems. April 2010.

Gas turbine image. (2014). Retrieved from http://www.power-technology.com/news/newsmott-macdonald appointed-as-owners-engineer-for-turkish-power-plant-4166799 
Inlets hoods deflectors. (n.d.). Retrieved from http://www.pneumafil.com/gas_turbine_inlet_air_filtration/ details/mist_control

Klima-Service. (n.d.). Classification of Filters, Filter Properties and Typical Examples of Use. Retrieved from http://www.ksklimaservice.com/

Milacron Marketing LLC. (n.d.). Industrial Washers and Cleaning Systems. Milacron Marketing LLC Technical Report No. 6/07 Page 1 of 2 Original 6/07.

Ultra-sonic cleaning system. (n.d.). Retrieved from http://www.caresonic.com/

\section{Copyrights}

Copyright for this article is retained by the author(s), with first publication rights granted to the journal.

This is an open-access article distributed under the terms and conditions of the Creative Commons Attribution license (http://creativecommons.org/licenses/by/4.0/). 